\title{
FLEXURAL PERFORMANCE OF CIRCULAR CONCRETE FILLED CFRP-STEEL TUBES
}

\author{
Q. L. Wang ${ }^{1, *}$ and Y. B. Shao ${ }^{2}$ \\ ${ }^{1}$ Professor, School of Civil Engineering, Shenyang Jianzhu University, Shenyang, P. R. China \\ ${ }^{2}$ Professor, School of Civil Engineering, Yantai University, Yantai, P. R. China \\ *(Corresponding author: E-mail: ceqlwang@sjzu.edu.cn)
}

Received: 26 September 2012; Revised: 15 January 2014; Accepted: 26 February 2014

\begin{abstract}
Sixteen circular concrete filled CFRP-steel tubular (C-CF-CFRP-ST) flexural members were tested. The test results indicate that the moment versus curvature curve at mid-span of C-CF-CFRP-ST members without longitudinal CFRP reinforcement is similar to such relationship of corresponding un-reinforced circular concrete filled steel tubular (C-CFST) flexural members. The moment versus curvature curve at mid-span for members with longitudinal CFRP reinforcement can be divided into following stages: elastic stage, elasto-plastic stage and softening stage. The longitudinal CFRP can enhance the stiffness of the specimens significantly. The steel tube and the CFRP tube could cooperate both in the transverse and in the longitudinal directions. The steel tube in the region under longitudinal tension has no confinement effect on the core concrete in the same tensile region because the concrete is in a state of contraction in transverse direction. The longitudinal strain distribution over depth of the specimens' cross-section satisfies the plane section assumption approximately. Finite element model is built and ABAQUS is used to analyze both the moment versus curvature curves at mid-span and the deformation of the C-CF-CFRP-ST flexural members. The finite element results are found to agree well with experimental results. Interaction forces exist both in the tensile region and in the compressive region between the outer tube and the concrete. However, there is essential difference between the interaction forces in the tensile region and in the compressive region respectively. Finally, flexural load carrying capacity of the C-CF-CFRP-ST is defined, and parametric equations for calculating it are presented. The accuracy and the reliability of the proposed equations are verified.
\end{abstract}

Keywords: Circular CFRP-steel tube, In-filled concrete, Beams, Flexural performances, Interaction force, Flexural load carrying capacity

\section{INTRODUCTION}

Concrete Filled Tubular structure (denoted by CFT structure, as shown in Figure 1) has aroused wide applications and deep studies all over the world for its advantage of high strength of tri-axially compressed concrete. Concrete Filled Steel Tubular structure (denoted by CFST structure, as shown in Figure 1 (a)) is a very typical CFT structure and it is used widely in civil engineering. The research work in this field has been studied systematically in the literature, such as the investigations on the static behavior (Han [1]; Tao et al. [2]; Georgios and Lam [3]; Uy [4]), the hysteretic behavior (Han and Yang [5]; Han and Li [6]) of the components and the connections, and fire and corrosion resistance (Han, Wang and Yu [7]; Han, Hou and Wang [8]). Nevertheless, Carbon Fiber Reinforced Polymer (denoted by CFRP) has been used in more and more engineering structures due to its advantages of high strength/weight ratio, good corrosion resistance, ease of installation, cheaper cost and so on. Concrete Filled CFRP Tubular structure (denoted by CF-CFRP-T structure, as shown in Figure $1(\mathrm{~b})$ ) is a typical example of CFRP structures (Wang and Restrepo [9]; Teng et al. [10]). However, the failure mode of CF-CFRP-T structure has brittle characteristics in most cases, and the load carrying capacity in the transverse direction for this structure is weak. There is also a new type of CFT structures, i.e., Concrete Filled CFRP-Steel Tubular structure (denoted by CF-CFRP-ST structure, as shown in Figure 1 (c)). CFRP can enhance load carrying capacity of the CFST structure and reduce local buckling of the steel tubes. It can also improve the structural durability. Comparing with CF-CFRP-T, CF-CFRP-ST has better ductility and shearing load carrying capacity. Additionally, CF-CFRP-ST can also provide a new approach to 
repair existing CFST with some slight damages (fire or corrosion) or with requirement to sustain more additional loads.

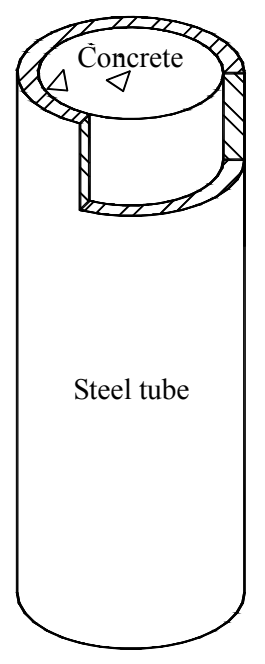

(a) CFST Structures

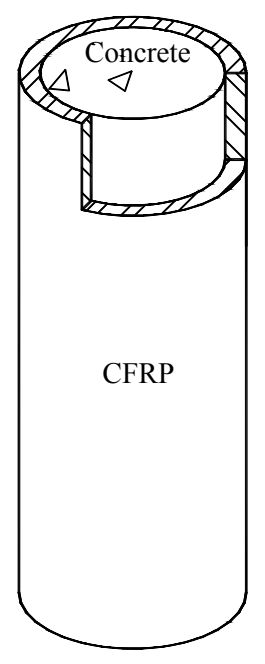

(b) CF-CFRP-T Structures

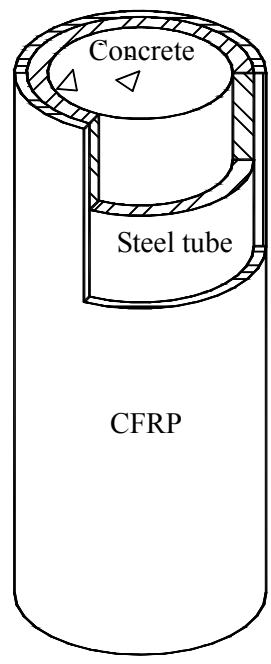

(c) CF-CFRP-ST Structures

Figure 1. CFT Structures

It is pointed out here that most resin as the matrix of CFRP composites has a poor fire-resistant capacity, and how to resolve the fire resistance of CFRP in engineering practice is still the primary concern. It is better to use CF-CFRP-ST in an environment with less fire but with severe corrosion, such as bridge engineering, offshore and ocean engineering and so on. From reported experiments under fire condition in the literature (Han, Tao and Wang [11]), it seems that CF-CFRP-ST has demonstrated satisfactory fire endurance under external loading when supplemental insulation to the CFRP composites has been used. Actually, the composite CFRP-metal tanks or tubes have been used in many fields, for example, gas tank used in motor vehicle, pipeline system for transporting high pressure gas or liquid used in municipal engineering or chemical engineering. Sometimes, steel petroleum pipeline system after corrosion is also reinforced with CFRP, which can save much cost compared to the measure of replacing the corroded tube with new one. Based on the above introduction, it is believed that the use of CF-CFRP-ST in civil engineering is quite reasonable and potential.

Some research studies in this field have been reported in the literature. Research work of using CFRP to repair CFST stub columns including circular specimens and square specimens after exposed to fire was conducted (Tao, Han and Wang [12]). A new CFST column system with circular cross-section, where CFRP materials were used as additional confinement to the potential plastic hinge regions of the composite column, was proposed (Xiao, He and Choi [13]), and a simplified analytical solution in association with a numerical computer program of the CF-CFRP-ST column was developed (Choi and Xiao [14]). Additionally, a systematic study on Circular CF-CFRP-ST (denoted by C-CF-CFRP-ST) stub columns has been carried out (Che, Wang and Shao [15]). The constitutive relationship of concrete confined by circular CFRP-steel tube under compression as well as the index of load carrying capacity of the axially compressed C-CF-CFRP-ST stub columns was presented. However, the performance of the C-CF-CFRP-ST flexural members or beam-columns is scarcely reported, although using CFRP wrapped in transverse direction to repair circular CFST (denoted by C-CFST) flexural members after exposed to fire was investigated (Tao, Han and Wang [12]). For the members carrying large bending 
moment, it is found that CFRP wrapped in transverse direction does not have remarkable efficiency, and in this situation CFRP is only necessary to be wrapped mainly in longitudinal direction. Furthermore, theoretical analysis on C-CF-CFRP-ST flexural members is also scarce.

In order to do some further studies and to understand the reinforcing efficiency of longitudinal CFRP, 16 C-CF-CFRP-ST flexural members with both transverse and longitudinal CFRPs are tested. Moment $(M)$ versus curvature $(\phi)$ curves at mid-span, cooperation between the steel tube and the CFRP, plane section assumption and stiffness of the composite members are all analyzed and discussed. Furthermore, the finite element software ABAQUS is used to simulate the deforming shape and the $M-\phi$ curves of the C-CF-CFRP-ST flexural members. The distributions of longitudinal stress and strain on the cross-section at mid-span, effect of the strengthening factor of the longitudinal CFRP $(\eta)$, and interaction force $(p)$ between core concrete and outer tube are also analyzed. Finally, the flexural load carrying capacity is defined, and a corresponding theoretical equation is presented.

\section{EXPERIMENTAL PROGRAM}

\subsection{Specimen Geometry}

In overall, sixteen C-CF-CFRP-ST flexural specimens were conducted, and the parameters include the number of longitudinal CFRP layer(s) $\left(m^{\prime}\right)$ and the outer diameter of the steel tube $\left(D_{\mathrm{s}}\right)$ respectively. Specimen details are provided in Table 1.

Table 1. Specimen Labels and Member Capacities

\begin{tabular}{|c|c|c|c|c|c|c|c|c|c|c|c|}
\hline No. & $\begin{array}{c}\text { Specimens } \\
\text { label }\end{array}$ & $\begin{array}{c}D_{\mathrm{s}} \\
(\mathrm{mm})\end{array}$ & $\begin{array}{c}t_{\mathrm{s}} \\
(\mathrm{mm})\end{array}$ & $\begin{array}{c}L \\
(\mathrm{~mm})\end{array}$ & $\begin{array}{c}L_{0} \\
(\mathrm{~mm})\end{array}$ & $\begin{array}{c}m^{\prime} \\
(\text { layer } \\
(\mathrm{s}))\end{array}$ & $\begin{array}{c}m \\
(\text { layer })\end{array}$ & $\begin{array}{c}M_{\mathrm{u}}{ }^{\mathrm{t}} \\
(\mathrm{kN} \cdot \mathrm{m})\end{array}$ & $\begin{array}{c}K_{\text {ie }} \\
\left(\mathrm{kN} \cdot \mathrm{m}^{2}\right)\end{array}$ & $\begin{array}{c}K_{\text {se }} \\
\left(\mathrm{kN} \cdot \mathrm{m}^{2}\right)\end{array}$ & $\begin{array}{c}\varepsilon_{\text {cflr }}{ }^{\prime} \\
(\mu \varepsilon)\end{array}$ \\
\hline 1 & CB A-0 & 89 & 4.5 & 1400 & 1200 & 0 & 1 & 12.5 & 225 & 221 & - \\
\hline 2 & CB A-1 & 89 & 4.5 & 1400 & 1200 & 1 & 1 & 14.2 & 231 & 226 & 12367 \\
\hline 3 & CB A-2 & 89 & 4.5 & 1400 & 1200 & 2 & 1 & 15.4 & 255 & 250 & 8581 \\
\hline 4 & CB A-3 & 89 & 4.5 & 1400 & 1200 & 3 & 1 & 17.5 & 277 & 259 & - \\
\hline 5 & CB B-0 & 108 & 4.5 & 1400 & 1200 & 0 & 1 & 18.5 & 457 & 465 & - \\
\hline 6 & CB B-1 & 108 & 4.5 & 1400 & 1200 & 1 & 1 & 19.9 & 505 & 474 & 9652 \\
\hline 7 & CB B-2 & 108 & 4.5 & 1400 & 1200 & 2 & 1 & 21.6 & 569 & 501 & 8795 \\
\hline 8 & CB B-3 & 108 & 4.5 & 1400 & 1200 & 3 & 1 & 24.2 & 853 & 509 & 9721 \\
\hline 9 & CB C-0 & 133 & 4.5 & 1400 & 1200 & 0 & 1 & 32.7 & 909 & 744 & - \\
\hline 10 & CB C-1 & 133 & 4.5 & 1400 & 1200 & 1 & 1 & 37.4 & 960 & 843 & 9913 \\
\hline 11 & CB C-2 & 133 & 4.5 & 1400 & 1200 & 2 & 1 & 37.4 & 992 & 860 & 8706 \\
\hline 12 & CB C-3 & 133 & 4.5 & 1400 & 1200 & 3 & 1 & 40.2 & 1009 & 898 & 9758 \\
\hline 13 & CB D-0 & 159 & 4.5 & 1400 & 1200 & 0 & 1 & 51.5 & 1721 & 1443 & - \\
\hline 14 & CB D-1 & 159 & 4.5 & 1400 & 1200 & 1 & 1 & 53.5 & 1715 & 1459 & 9603 \\
\hline 15 & CB D-2 & 159 & 4.5 & 1400 & 1200 & 2 & 1 & 59.6 & 1746 & 1542 & 9211 \\
\hline 16 & CB D-3 & 159 & 4.5 & 1400 & 1200 & 3 & 1 & 64.2 & 1757 & 1627 & 12041 \\
\hline
\end{tabular}

In Table 1, "CB" in the specimen's label refers to Circular Beam, and the third letter can be anyone among letters "A", "B", "C" or "D" which denotes different $D_{\text {s }}$ with its value equal to $89 \mathrm{~mm}$, $108 \mathrm{~mm}, 133 \mathrm{~mm}$ or $159 \mathrm{~mm}$ respectively. The number in the specimen label with " 0 ", "1", "2" or " 3 " refers to the value of $m^{\prime}$. For other parameters, $t_{\mathrm{s}}$ is wall thickness of the steel tube, $L$ is length of the specimens, $L_{0}$ is net span of the specimens, and $m$ is number of the transverse CFRP layer. 


\subsection{Specimen Preparations}

Fabrication of C-CFST specimens can be found in reported reference (Han [1]). Carbon fiber sheets are applied using a hand lay-up method. The longitudinal CFRP is glued firstly, and the transverse CFRP is then placed sequentially. The final end of a sheet is overlapped the initial end by $150 \mathrm{~mm}$. Some specimens before testing are shown in Figure 2.

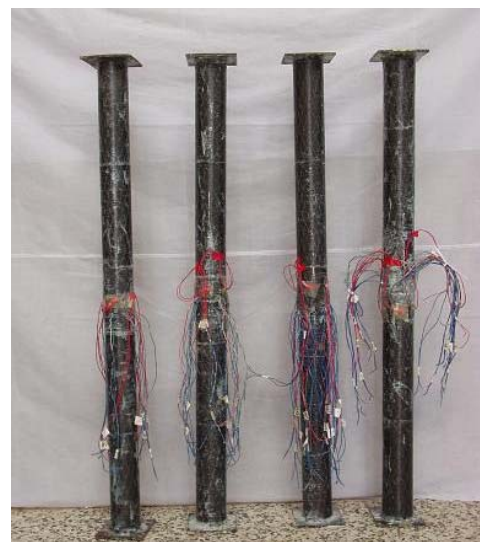

(a) $D_{\mathrm{s}}=89 \mathrm{~mm}$ Specimens

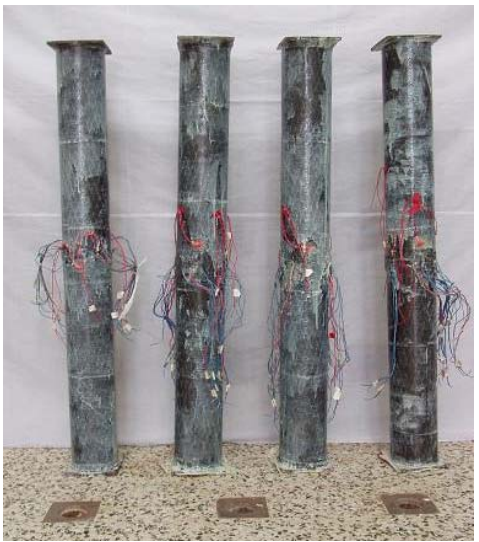

(b) $D_{\mathrm{s}}=159 \mathrm{~mm}$ Specimens

Figure 2. Several Specimens before Testing

\subsection{Material Properties}

Tensile tests on steel coupons cut from the original seamless steel tubes are conducted to measure the material properties. The tested results are given in Table 2, where $E_{\mathrm{s}}, f_{\mathrm{y}}, v_{\mathrm{s}}$ and $f_{\mathrm{u}}$ are elastic modulus, yield stress, Poisson's ratio and ultimate stress of the steel tube respectively.

Table 2. Material Properties of Steel Tube

\begin{tabular}{|c|c|c|c|c|}
\hline$D_{\mathrm{s}}(\mathrm{mm})$ & $E_{\mathrm{s}}(\mathrm{GPa})$ & $f_{\mathrm{y}}(\mathrm{MPa})$ & $v_{\mathrm{s}}$ & $f_{\mathrm{u}}(\mathrm{MPa})$ \\
\hline 89 & 216 & 304 & 0.26 & 465 \\
\hline 108 & 216 & 269 & 0.25 & 434 \\
\hline 133 & 216 & 333 & 0.27 & 474 \\
\hline 159 & 217 & 333 & 0.31 & 474 \\
\hline
\end{tabular}

All the specimens were cast with same concrete. In the concrete mixture, Portland cement was used, and fine aggregate was silica-based sand. The course aggregate was limestone with the largest size of $20 \mathrm{~mm}$, and $1 \%$ (in weight) water reducing agent was added. The mixture proportion of the concrete is summarized in Table 3.

Table 3. Mixture Proportions of Concrete $\left(\mathrm{kg} \cdot \mathrm{m}^{-3}\right)$

\begin{tabular}{|c|c|c|c|}
\hline Cement & Water & Fine aggregate & Course aggregate \\
\hline 485 & 150 & 703 & 1062 \\
\hline
\end{tabular}

To determine the compressive strength of the concrete, six $150 \mathrm{~mm}$ cubic specimens were cast and cured in conditions similar to that of the tested specimens. The average cubic strength $\left(f_{\mathrm{cu}}\right)$ at 28 days was $48.8 \mathrm{MPa}$. At the time of tests (six months later due to the delay of the test program), the cubic strength of $60.7 \mathrm{MPa}$ was achieved and this strength is used in following FE simulation and 
calculation of flexural load carrying capacity. Elastic modulus of the concrete $\left(E_{\mathrm{c}}\right)$ was $35.9 \mathrm{GPa}$.

The used carbon fiber sheet is made in EPO Company, Germany, which is a kind of one-way sheet. The material properties of the CFRP in tension, determined from tensile tests of six flat coupons (as shown in Figure 3), are given in Table 4 , where $f_{\mathrm{cf}}{ }^{\prime}, E_{\mathrm{cf}}, \delta_{\mathrm{cf}}$ and $w_{\mathrm{cf}}$ are tensile strength, elastic modulus, elongation percentage and density of the carbon fiber sheet respectively, and $t_{\mathrm{cf}}$ is thickness of one layer carbon fiber sheet.

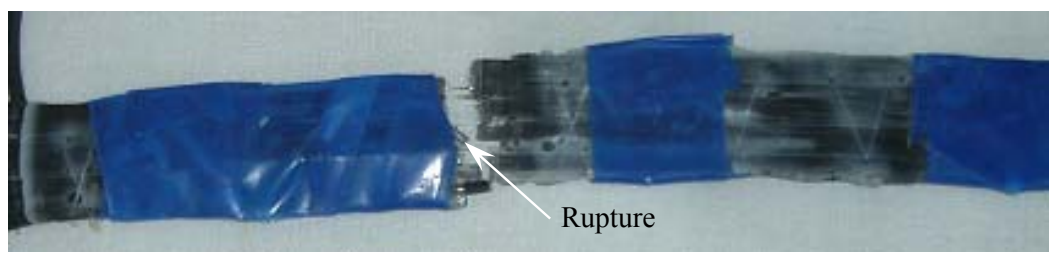

Figure 3. Typical Failed CFRP Coupon

Table 4. Main Technical Properties of Carbon Fiber Sheets

\begin{tabular}{|c|c|c|c|c|c|}
\hline Model number & $f_{\mathrm{cf}}{ }^{\prime}(\mathrm{GPa})$ & $E_{\mathrm{cf}}(\mathrm{GPa})$ & $\delta_{\mathrm{cf}}(\%)$ & $w_{\mathrm{cf}}\left(\mathrm{g} \cdot \mathrm{m}^{-2}\right)$ & $t_{\mathrm{cf}}(\mathrm{mm})$ \\
\hline $\mathrm{C} 300 / 300$ & 4.83 & 230 & 2.1 & 300 & 0.167 \\
\hline
\end{tabular}

JGN-C, a kind of epoxy resin used for building structures produced by Building Science Research Institute of Liaoning Province, P. R. China, was used for adhering the CFRP to the steel tube. Another epoxy resin, JGN-P, was also used for gluing CFRPs together.

\subsection{Test Setup and Instrumentation}

The experimental test was carried out in the Structural Engineering Laboratory of Shenyang Jianzhu University, P. R. China. As shown in Figure 4, the specimen is simply supported at both ends. A jack which is located at the mid-span of the specimen is used to apply lateral load $(P)$, and the load is transferred by a spread beam with enough stiffness to the two tri-span points of the specimen. The load is applied in several steps. In the elastic stage, each loading step is $5.0 \mathrm{kN}$. When the applied load is about $60 \%$ of the estimated flexural load carrying capacity, the magnitude of the loading step reduces. The estimated flexural load carrying capacity is obtained by the following method: the transverse and the longitudinal CFRPs are transferred to equivalent steel tube, and then the flexural load carrying capacity can be calculated by using corresponding equations of C-CFST flexural members (Han [16]). However, the equivalent steel tube besides longitudinal CFRP is not considered in calculating the confinement factor of the steel tube $\left(\xi_{\mathrm{s}}\right)$ (Han [17]). After the deflection at the mid-span exceeds $L_{0} / 50$, displacement control is used till failure.

A force transducer with a capacity of $600 \mathrm{kN}$ was used to measure the loading magnitude. Three Linear Variable Differential Transformers (LVDTs) were placed to measure the deflection of the specimens. At the two supporting points, two LVDTs were also used to measure the settlements. Overall 11 strain gauges were glued on the surfaces of each steel tube and the CFRP around cross-section at mid-span of the specimens respectively, as shown in Figure 5, where points 1-7 were the locations for measuring longitudinal strains and points $1,3,5$ and 8 were the locations for measuring transverse strain. 


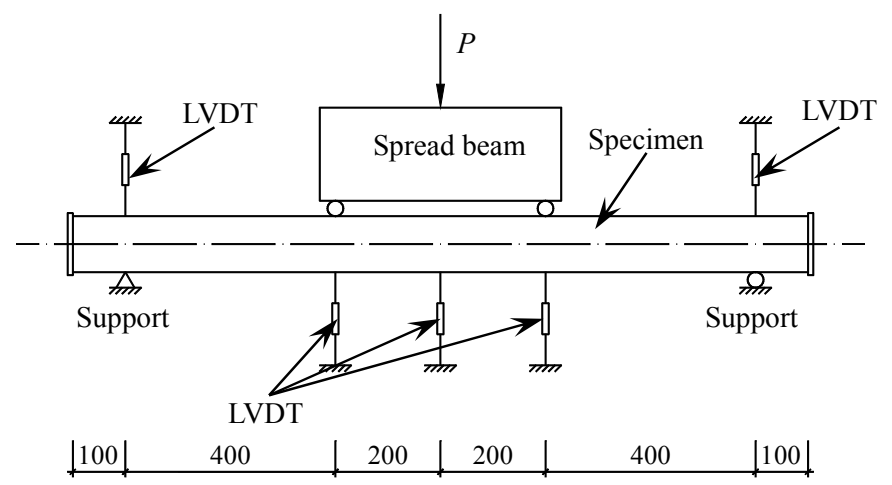

(a) General Placement (in $\mathrm{mm}$ )

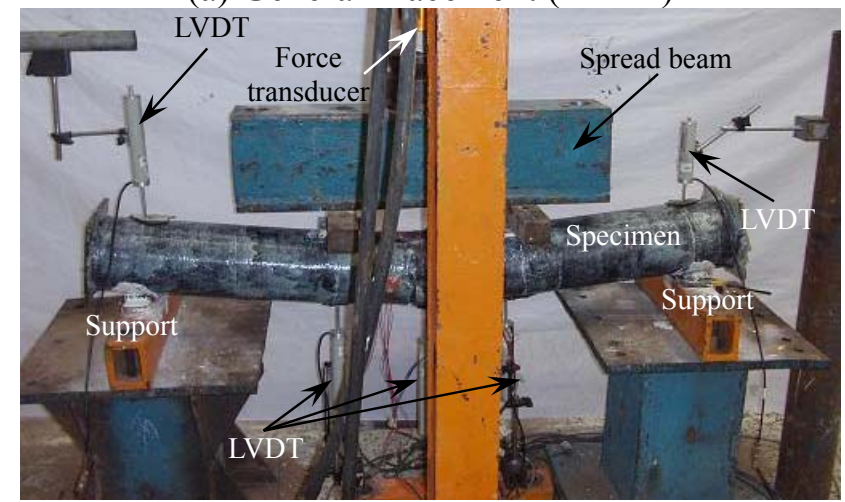

(b) Test Figure

Figure 4. Test Arrangement

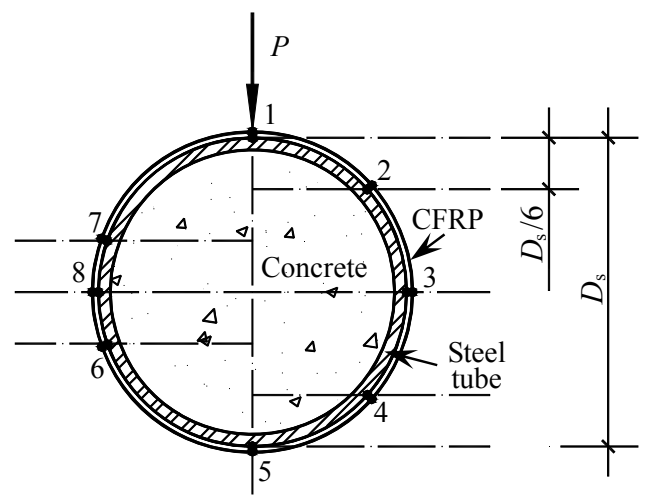

Figure 5. The Location of Strain Gauges

The data was captured and saved by data acquisition system U-CAM-70A, and the load $(P)$ versus deflection $\left(u_{\mathrm{m}}\right)$ at mid-span curve was obtained simultaneously.

\subsection{Test Observations and Failure Modes}

For the specimens only reinforced with transverse CFRP, the failure process is gradual. During the initial loading stage, in general, the bending load presents an approximately proportional relationship to $u_{\mathrm{m}}$. There are no obvious damages in the appearance of the specimens. New cracks between carbon fibers and extensions of existing cracks are observed during further loading. At the end of the tests, through-cracks are observed on the CFRP jackets in the pure-bending region and large deformation of the specimen appears. Finally, the transverse CFRP located at longitudinally compressed region begins to rupture as shown in Figure 6 (a). 


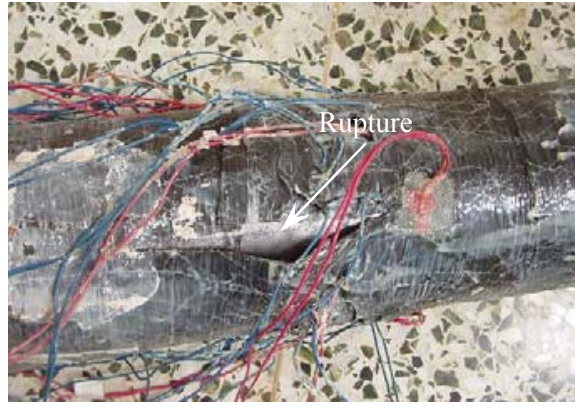

(a) Transverse CFRP

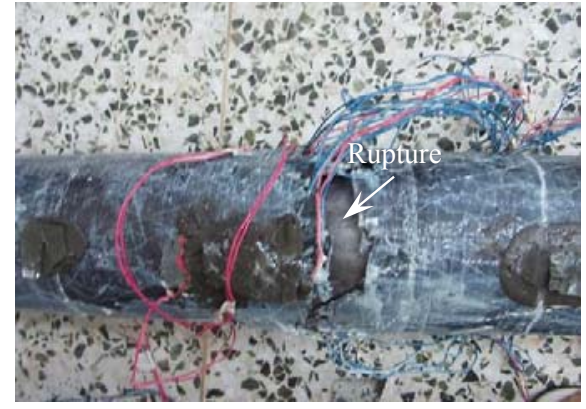

(b) Longitudinal CFRP

Figure 6. Rupture of CFRPs

For those specimens reinforced with longitudinal CFRP, longitudinal CFRP begins to rupture when the strain at the extreme fiber of the tensile region reaches about $10000 \mu \varepsilon$, which can be seen in Figure 6 (b). At this time, the flexural load carrying capacity of the beam decreases suddenly. The transverse CFRP located at longitudinally compressive region begins to rupture when the deformation of the specimen becomes larger in the later loading stage. The final failure modes of several specimens are shown in Fig. 7.

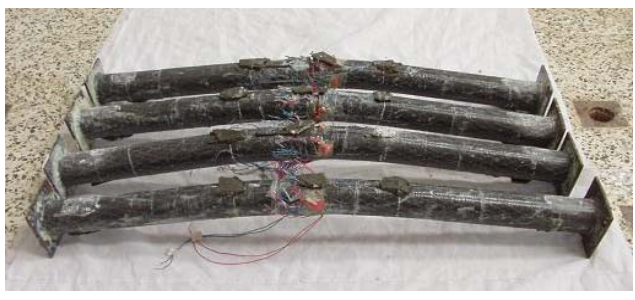

(a) $D_{\mathrm{s}}=89 \mathrm{~mm}$ Specimens

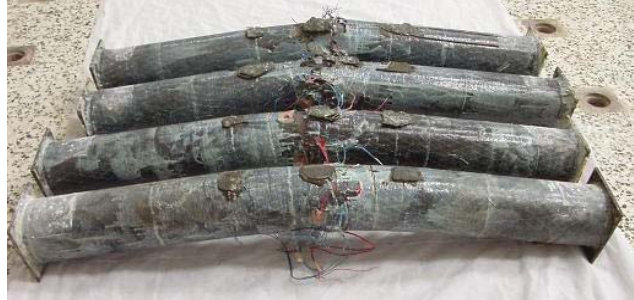

(b) $D_{\mathrm{s}}=159 \mathrm{~mm}$ Specimens

Figure 7. Typical Deformation of Several Specimens

The specimens are cut into two halves after the tests, as shown in Figure 8, to find that the concrete can be divided into both tensile and compressive regions. It can be seen that the concrete in longitudinally tensile region has some cracks while it is crushed in the region under longitudinal compression.

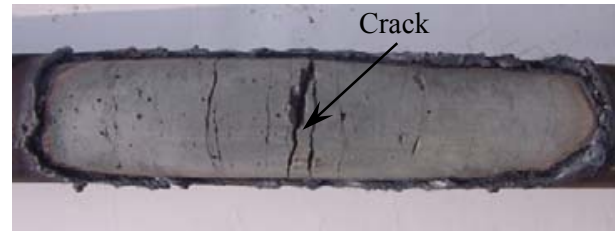

(a) Longitudinally Tensioned Concrete

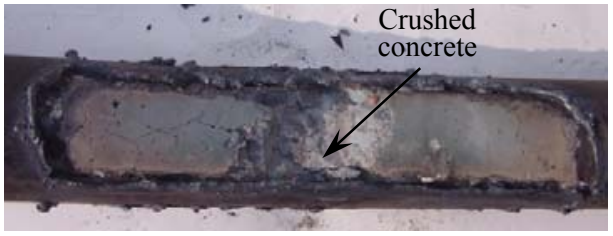

(b) Longitudinally Compressed Concrete

Figure 8. Failure Modes of Concrete 


\subsection{Test Results and Analysis}

\subsubsection{Tested $M-\phi$ curves}

Figure 9 shows the deflection $(u)$ curves of specimen CB D-3, where $M_{\mathrm{u}}{ }^{\mathrm{t}}$ is tested value of the flexural load carrying capacity $\left(M_{\mathrm{u}}\right)$. All values of $M_{\mathrm{u}}{ }^{\mathrm{t}}$ are listed in Table 1 . From Figure 9, it is found that the deflection of each specimen is very close to half sinusoidal curve. Therefore, $\phi$ can be calculated from $u_{\mathrm{m}}$ approximately according to the following equation (Han, Yao and Zhao [18])

$\phi=\pi^{2} u_{\mathrm{m}} / L_{0}{ }^{2}$

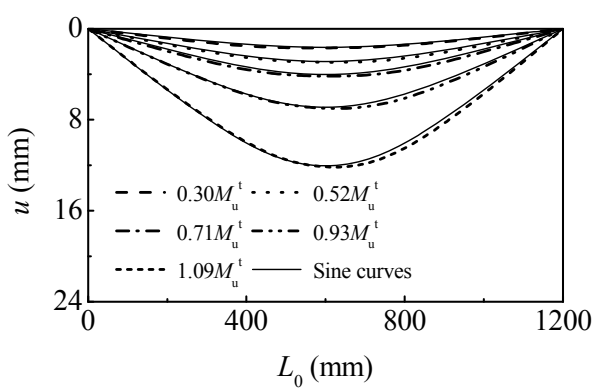

(a) Before Rupture of Longitudinal CFRP

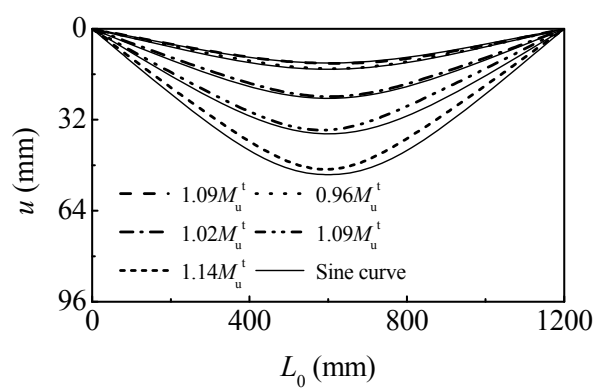

(b) After Rupture of Longitudinal CFRP

Figure 9. Deflection Curves of Specimen CB D-3

Figure 10 shows the $M-\phi$ curves at mid-span of the specimens, where

$$
M=P L_{0} / 6
$$

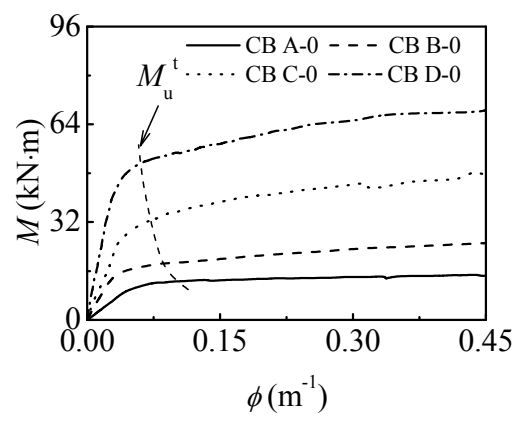

(a) $m^{\prime}=0$

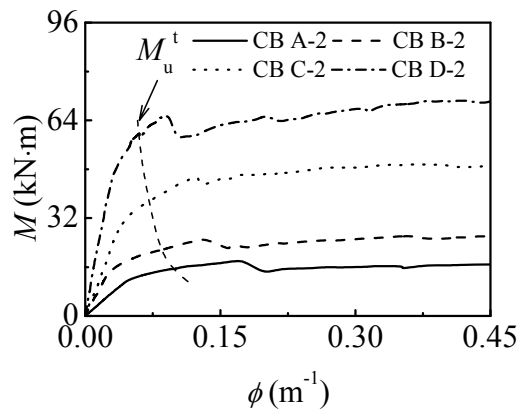

(c) $m^{\prime}=2$

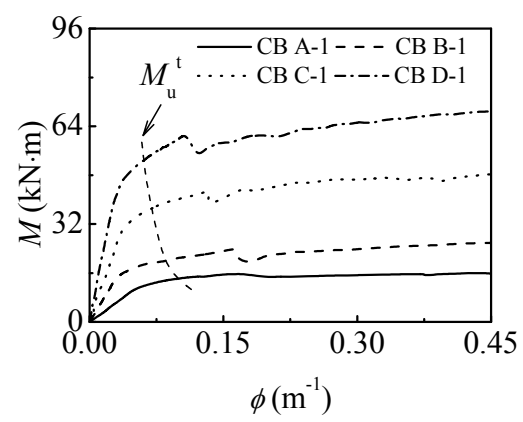

(b) $m^{\prime}=1$

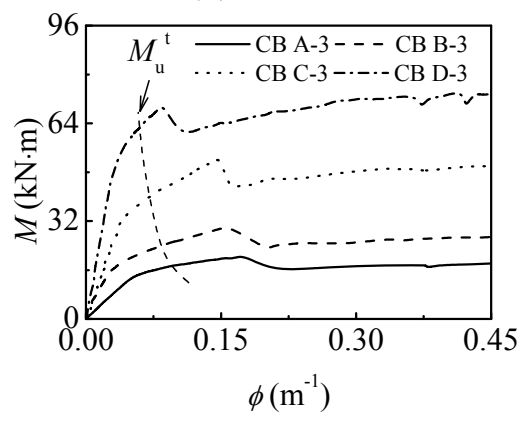

(d) $m^{\prime}=3$

Figure 10. Tested $M-\phi$ Curves 
It is found that parameter $m^{\prime}$ has a remarkable effect on the curve shape of the C-CF-CFRP-ST flexural members. For specimens with $m^{\prime}=0$, their curves are similar to those of the corresponding C-CFST flexural members (Han [16]). While for specimens with $m^{\prime} \neq 0$, both the load and the deflection are smaller during the initial loading stage, and the relationship between them is approximately linear. This stage belongs to elastic stage. As load increases continuously, the deflection increases much more rapidly than before, and this stage belongs to elasto-plastic stage. The curve falls in softening stage after the longitudinal CFRP is ruptured, and the rest of the curves are similar to those of the corresponding C-CFST flexural members. For the specimens with $m^{\prime} \neq 0$, their failure seems to be brittle. However, due to the existence of the steel tube, the specimens could still keep high flexural load carrying capacity even they are suffered from a large deformation.

\subsubsection{Stiffness}

According to the $M-\phi$ curves shown in Figure 10, the initial flexural stiffness $\left(K_{\text {ie }}\right)$ and the service flexural stiffness $\left(K_{\mathrm{se}}\right)$ (Verma et al. [19]) are defined. The relationship of $K_{\mathrm{ie}}-m^{\prime}$ and $K_{\mathrm{se}}-m^{\prime}$ is illustrated in Figure 11. $K_{\mathrm{ie}}$ and $K_{\mathrm{se}}$ are also listed in Table 1. As show in Figure 11, $K_{\text {ie }}$ and $K_{\text {se }}$ are both enhanced by the increase of $m^{\prime}$. It is clear that the longitudinal CFRP can enhance the stiffness of the specimens significantly.

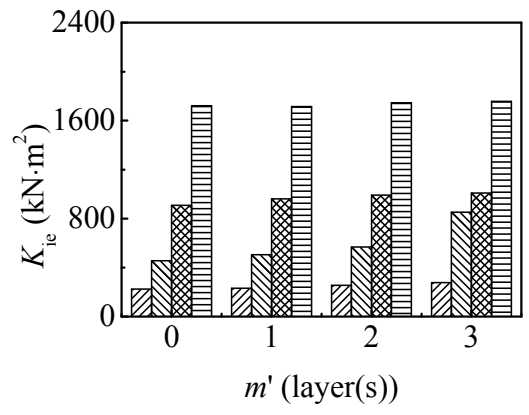

पIIIA $D_{\mathrm{s}}=89 \mathrm{~mm}$ Specimens

MII $D_{\mathrm{s}}=108 \mathrm{~mm}$ Specimens

$D_{\mathrm{s}}=133 \mathrm{~mm}$ Specimens

高 $D_{\mathrm{s}}=159 \mathrm{~mm}$ Specimens

(a) Histogram of $K_{\mathrm{ie}}-m^{\prime}$

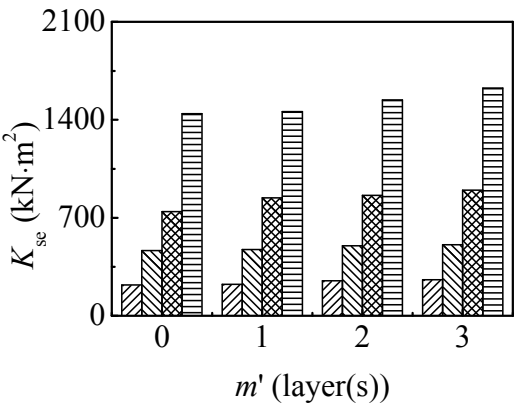

VIIII $D_{\mathrm{s}}=89 \mathrm{~mm}$ Spesimens

W $D_{\mathrm{s}}=108 \mathrm{~mm}$ Specimens

$D_{\mathrm{s}}=133 \mathrm{~mm}$ Specimens

Е $D_{\mathrm{s}}=159 \mathrm{~mm}$ Specimens

(b) Histogram of $K_{\mathrm{se}}-m^{\prime}$

Figure 11. Stiffness versus $m^{\prime}$ Relationship

\subsubsection{Cooperation between Steel Tube and CFRP}

Figure 12 shows the comparison of strains between the steel tube and the CFRP, where $\varepsilon_{1}$ and $\varepsilon_{\mathrm{t}}$ are longitudinal and transverse strains respectively. Similarly, $\varepsilon_{\mathrm{s} 1}$ and $\varepsilon_{\mathrm{cfl}}$ are longitudinal strains of the steel tube and the CFRP respectively, and $\varepsilon_{\text {st }}$ and $\varepsilon_{\text {cft }}$ are transverse strains of the steel tube and the CFRP respectively. As shown in Figure 12, $\varepsilon_{\mathrm{sl}}$ and $\varepsilon_{\mathrm{cfl}}$ are basically the same, and 
so is the relationship between $\varepsilon_{\mathrm{st}}$ and $\varepsilon_{\mathrm{cft}}$. Additionally, from the observation of the cut CFRP-steel tubes after the experiment, it is found that the adherence between the CFRP and the steel tube is still intact except in the region where CFRP is ruptured. All above results indicate that steel tubes and CFRP can cooperate well in both longitudinal and transverse directions. Otherwise, as shown in Figure 12 (b), the distribution of transverse strains around the cross-section is not uniform: largest transversely tensile and compressive strains are located at point 5 and at point 1 respectively. Actually, the outer tube can be divided into a tensile region and a compressive region in transverse direction. Such classification depends on the fact that the outer tube is under tension or under compression in longitudinal direction. As the specimen is subjected to bending moment, part of the cross-section of the outer tube is under compression in longitudinal direction, which causes this part of the cross-section under tension in transverse direction. Accordingly, the other part of the cross-section of the outer tube is under tension in longitudinal direction, which causes this part of the cross-section under compression in transverse direction. This phenomenon has been proved from experimental measurement. Due to the above reason, the outer tube compressed transversely does not provide confinement effect for the concrete.

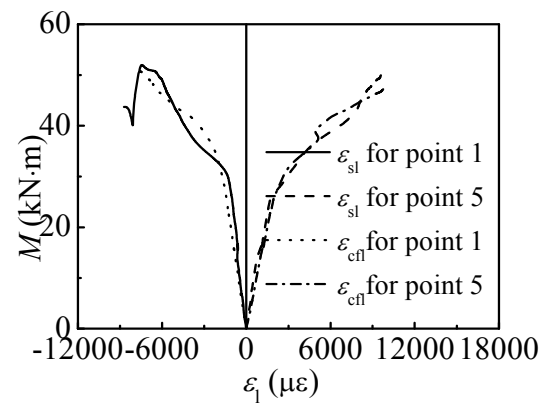

(a) $M-\varepsilon_{1}$ Curves of Specimen CB C-3

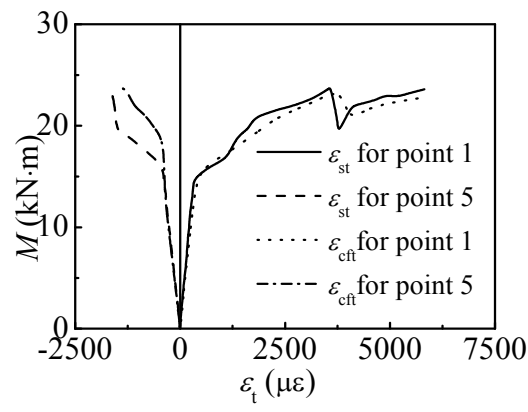

(b) $M-\varepsilon_{\mathrm{t}}$ Curves of Specimen CB B-1

Figure 12. Comparisons of Strains between Steel Tube and CFRP

\subsubsection{Plane Section Assumption}

Figure 13 shows the distribution of $\varepsilon_{\mathrm{s} 1}$ over depth of the cross-section of the specimen with $D_{\mathrm{s}}=133 \mathrm{~mm}$, where $\Delta_{\mathrm{cn}}$ is the distance measured from the neutral axis to the centroid axis. The distribution of $\varepsilon_{\mathrm{sl}}$ is basically in accordance with the plane section assumption. The neutral axis moves toward the compsession region gradually as the moment increases.

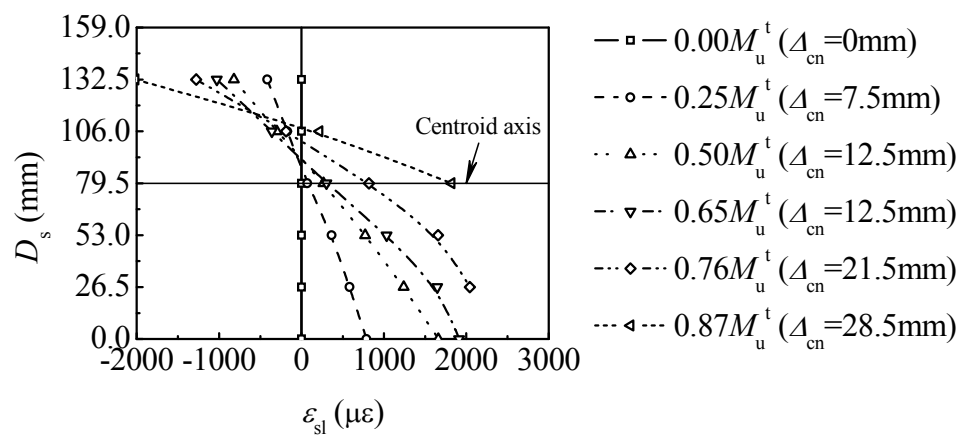

(a) Specimen CB D-0 


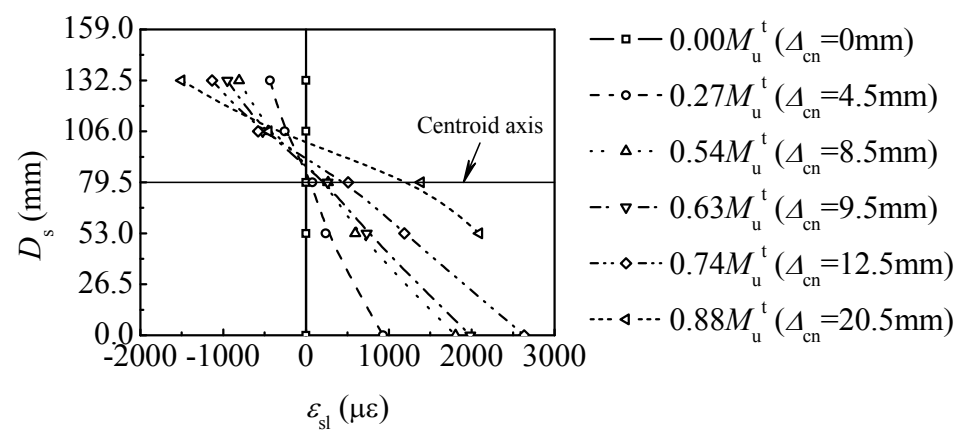

(b) Specimen CB D-1

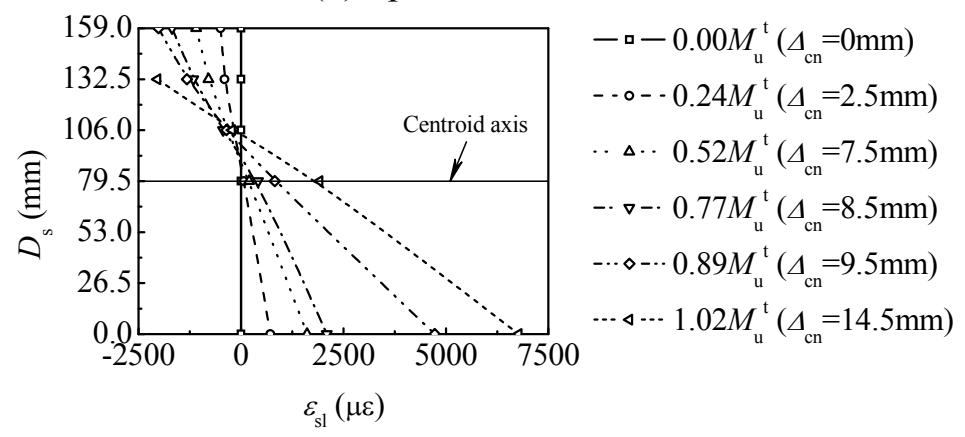

(c) Specimen CB D-2

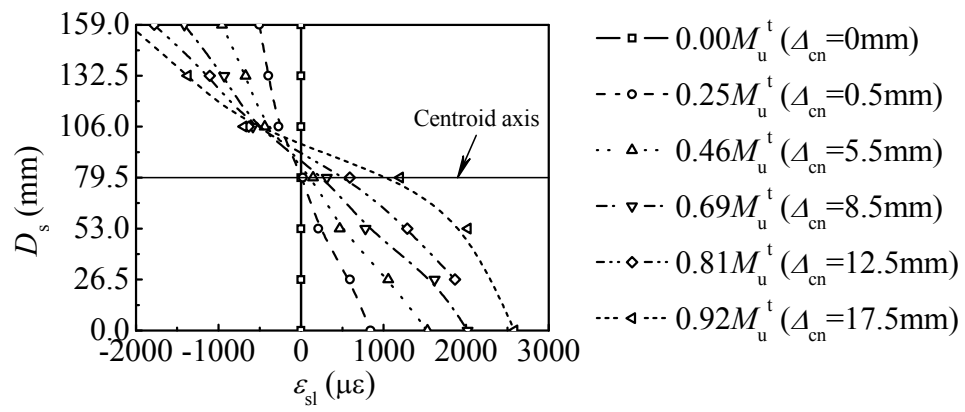

(d) Specimen CB D-3

Figure 13. Distribution of $\varepsilon_{\mathrm{sl}}$ over Depth on Cross-Section of Specimens with $D_{\mathrm{s}}=133 \mathrm{~mm}$

\section{FE SIMULATION}

\subsection{Stress-Strain Relationship of Materials}

A 5-stage stress-strain relationship of steel material (Han, Yao and Tao [20]) is used here. This stress-strain curve includes 5 segments: linear and elastic stage, nonlinear but elastic stage, plastic flowing stage, hardening stage and softening stage. The constitutive relationship of concrete confined by CFRP-steel tube under compression as well as under tension (Che, Wang and Shao [15]) is adopted. CFRP is assumed to be only able to sustain tension. Before fracture, the stress-strain relationship of CFRP is in accordance with Hooke's Law as follow

$$
\sigma_{\mathrm{cf}}=E_{\mathrm{cf}} \varepsilon_{\mathrm{cf}}
$$

where $\sigma_{\mathrm{cf}}$ and $\varepsilon_{\mathrm{cf}}$ are the stress and strain of CFRP respectively. 
When longitudinal CFRP reaches its rupture strain $\left(\varepsilon_{\mathrm{cffl}},=10000 \mu \varepsilon\right.$. Rupture strain of the longitudinal CFRP for each specimen measured from experimental test ( $\left.\varepsilon_{\text {cflr }}{ }^{\prime}\right)$ is tabulated in Table 1. The value of $\varepsilon_{\text {cffr }}$ is determined from the average value of all measured $\varepsilon_{\text {cflr }}{ }^{\prime}$ ), it loses longitudinal strengthening effect to the members. However, when transverse CFRP reaches its rupture strain $\left(\varepsilon_{\text {cftr }},=5500 \mu \varepsilon\right)($ Che, Wang and Shao [15]), it loses transverse confinement to the steel tube.

An interesting point is stressed here that CFRP has three rupture strains, i. e., for the transverse CFRP, $\varepsilon_{\text {cftr }}=5500 \mu \varepsilon, \phi=12.5-22.5 \mathrm{~m}^{-1}$; for the longitudinal CFRP, $\varepsilon_{\text {cflr }}=10000 \mu \varepsilon$, $\phi=0.1-0.2 \mathrm{~m}^{-1}$; while for the CFRP coupon, $\delta_{\mathrm{cf}}=2.1 \%=21000 \mu \varepsilon, \phi=0$. This means the rupture strain may decrease with a bigger curvature. Similar conclusion can be found from the reported research work (Yu et al. [21]). The above defined rupture strains of the CFRPs in longitudinal and in transverse directions are used in finite element simulation.

In the research work on CFST (Han [17]), the confinement of steel tube to concrete is represented by a confinement factor of the steel tube $\left(\xi_{\mathrm{s}}\right)$. Similarly, the confinement of the transverse CFRP can be also represented by a confinement factor of the transverse CFRP $\left(\xi_{\text {cf }}\right)$ (Che, Wang and Shao [15]), and the strengthening efficiency of longitudinal CFRP may be represented by a strengthening factor of the longitudinal CFRP $(\eta)$. The definitions of all the confinement or strengthening factors are listed as follows:

$\xi_{\mathrm{s}}=A_{\mathrm{s}} f_{\mathrm{y}} /\left(A_{\mathrm{c}} f_{\mathrm{ck}}\right)$

$f_{\mathrm{ck}}=0.67 f_{\mathrm{cu}}$

$\xi_{\mathrm{cf}}=A_{\mathrm{cft}} f_{\mathrm{cft}} /\left(A_{\mathrm{c}} f_{\mathrm{ck}}\right)$

$f_{\mathrm{cft}}=E_{\mathrm{cf}} \varepsilon_{\mathrm{cftr}}=1260 \mathrm{MPa}$

$\eta=A_{\text {cfl }} f_{\text {cfl }} /\left(A_{\mathrm{s}} f_{\mathrm{y}}\right)$

$f_{\mathrm{cfl}}=E_{\mathrm{cf}} \varepsilon_{\mathrm{cflr}}=2300 \mathrm{MPa}$

where $A_{\mathrm{s}}$ is cross-sectional area of the steel tube; $A_{\mathrm{c}}$ and $f_{\mathrm{ck}}$ are cross-sectional area and characteristic axial compressive strength of the concrete respectively; $A_{\text {cft }}$ and $f_{\text {cft }}$ are cross-sectional area and ultimate tensile strength of the transverse CFRP respectively; $A_{\mathrm{cfl}}$ and $f_{\text {cfl }}$ are cross-sectional area and ultimate tensile strength of the longitudinal CFRP respectively.

\subsection{FE Model}

\subsubsection{Element type selection}

Shell element S4 with full integration is selected for discretizing the steel tube in finite element model. Simpson integration with 9 integrating points in the shell thickness direction is used. For the core concrete, 3-D brick elements C3D8R with reduced integration are used. Membrane element 
M3D4 with 4-nodes is used for modelling CFRP.

\subsubsection{Mesh discritization}

The convergent analysis is carried out by using refined mesh in finite element analysis, and the details can be referred to relative research (Che, Wang and Shao [15]). Figure 14 shows the FE mesh of a typical model.

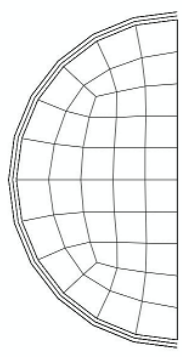

(a) Transverse Element

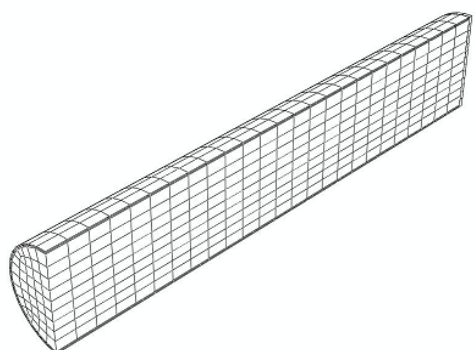

(b) Longitudinal Element

Figure 14. Mesh Discritization

\subsubsection{Interface model}

Hard contact is used for defining contact interface between steel tube and concrete, i.e., the pressure perpendicular to the contact surfaces $(p)$ can be transferred completely between the two surfaces (Han, Liu and Yang [22]). The tangential force between the steel tube and the concrete surface is simulated by using Columb model, i.e., shear force can be transferred between surfaces (Han, Liu and Yang [22]). In the experimental tests, CFRP is bound to the steel tube, and it is assumed that no slip exists between CFRP and the steel tube. Same nodal freedoms are used for the contact elements between CFRP and the steel tube. In the tangential direction of the contact surfaces between the end plate and the concrete, there is also no slipping, and hard contact assumption is used in normal direction of the contact surfaces.

\subsubsection{Boundary conditions}

Boundary conditions are shown in Figure15, which are in accordance with experimental process. According to the symmetry of both the geometry and the boundary condition, $1 / 4$ model is selected for FE analysis. On the symmetrical plane of the model, symmetrical constraints are applied. The displacement in $y$-direction at the supporting points is constrained.

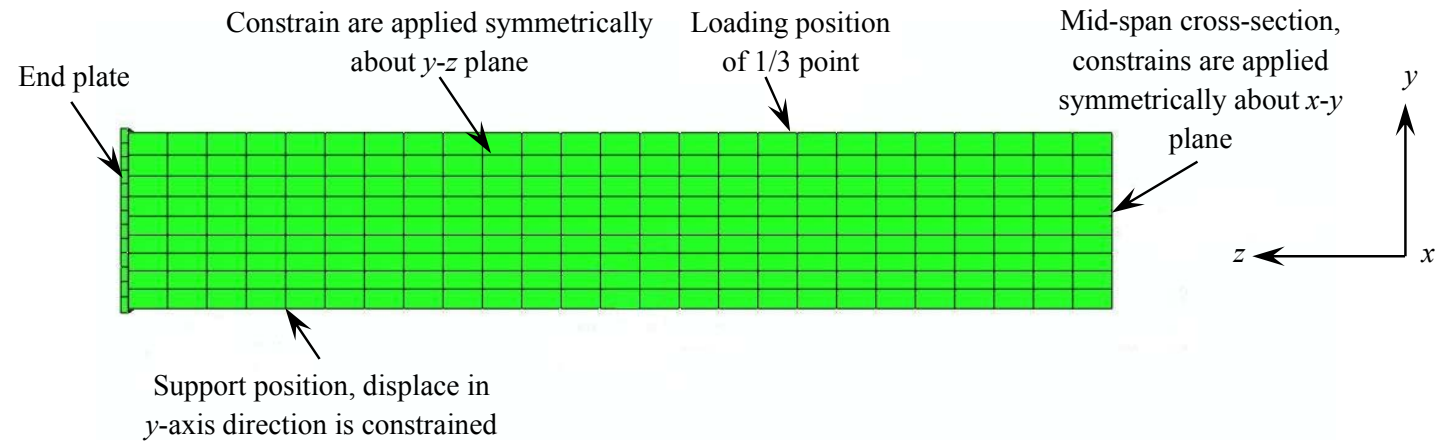

Figure 15. Boundary Conditions 


\subsection{FE Results}

\subsubsection{Failure modes}

To verify the reliability of the above presented FE method, overall 16 C-CF-CFRP-ST flexural specimens are analyzed by using ABAQUS software. Figure 16 shows the deformation obtained from experimental test and FE simulation. From Figure 16, it can be found that the FE predicted deformation of the specimen is quite similar to the experimental observation.

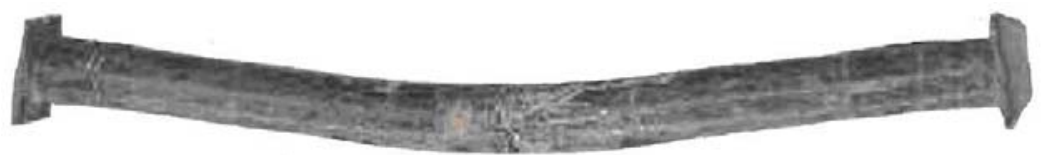

(a) Experimental Result

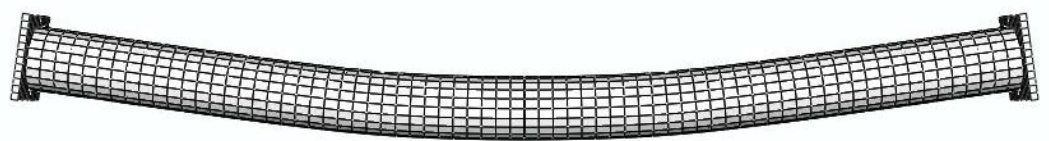

(b) Simulated Result

Figure 16. Comparison of Deformations

\subsubsection{M- $\phi$ curves}

The FE $M-\phi$ curves together with the experimentally measured results are plotted in Figure 17. In the FE simulation, the deflection of the specimens can be obtained from FE analysis, and the curvature is then calculated from Eq. (1). It can be found from Figure 17 that the FE results are reasonable compared with the experimental results although the FE predictions seem to be a little lower.

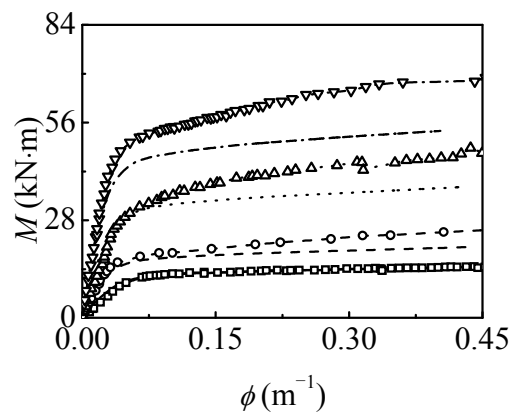

- FE result of specimen $\mathrm{CB} A-0$

- - - - FE result of specimen $\mathrm{CB}$ B-0

$\cdots \cdot$ FE result of specimen $\mathrm{CB} C-0$

-.-. FE result of specimen CB D-0

$-\mathbf{-}-$ Test result of specimen CB A-0

- - - - Test result of specimen CB B-0

$\cdots \Delta$. Test result of specimen CB C-0

$-\cdot \nabla-\cdot$ Test result of specimen CB D-0

(a) $m^{\prime}=0$

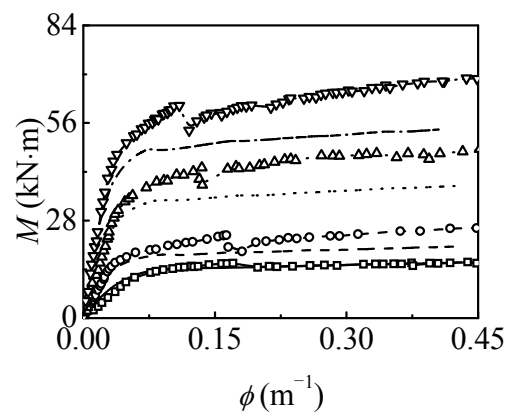

- FE result of specimen CB A-1

- - - - FE result of specimen CB B-1

$\cdots \cdot$ FE result of specimen $\mathrm{CB}$ C-1

-.-.- FE result of specimen CB D-1

- - Test result of specimen CB A-1

- - ०- Test result of specimen CB B-1

$\cdots \Delta$. Test result of specimen CB C-1

$-\cdot \nabla-\cdot$ Test result of specimen CB D-1

(b) $m^{\prime}=1$ 


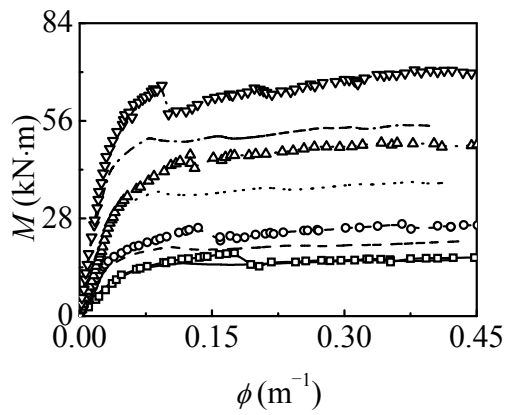

- FE result of specimen CB A-2

- - - - FE result of specimen $\mathrm{CB}$ B-2

$\cdots \cdots$ FE result of specimen $\mathrm{CB} \mathrm{C}-2$

-.-.- FE result of specimen CB D-2

- - Test result of specimen CB A-2

- o- $\cdot$ Test result of specimen CB B-2

$\cdots \Delta$. Test result of specimen $\mathrm{CB} \mathrm{C}-2$

$-\cdot \nabla-\cdot$ Test result of specimen CB D-2

(c) $m^{\prime}=2$

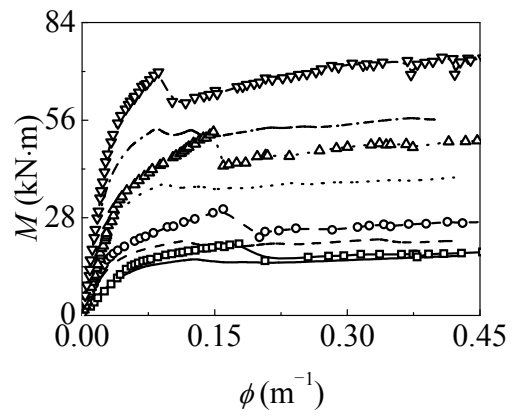

- FE result of specimen $\mathrm{CB} A-3$

- - - - FE result of specimen $\mathrm{CB}$ B-3

$\cdots \cdots$ FE result of specimen $\mathrm{CB} C-3$

-.-.- FE result of specimen $\mathrm{CB}$ D-3

- $\mathbf{-}$ - Test result of specimen CB A-3

$-\cdot \circ-\cdot$ Test result of specimen CB B-3

$\cdots \Delta$. Test result of specimen CB C-3

$-\cdot \nabla-\cdot$ Test result of specimen CB D-3

(d) $m^{\prime}=3$

Figure 17. Comparison of $M-\phi$ Curves between FE Result and Experimental Result

\section{THEORETICAL ANALYSIS}

Three typical points, as shown in Figure 18, are selected for discussion: at point 1, the tensile extreme fiber of the steel tube reaches its proportional limit; at point 2, longitudinal CFRP is fractured; and at point 3 , the deflection at the mid-span is about $L_{0} / 25$.

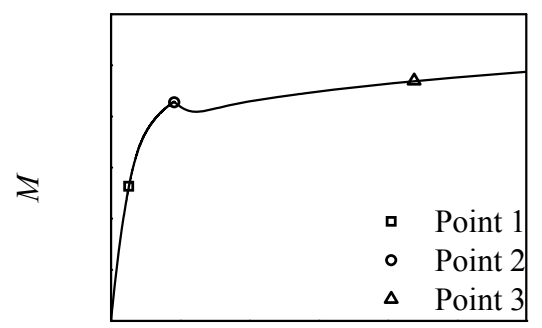

$\phi$

Figure 18. Typical Points in $M-\phi$ Curve

\subsection{Longitudinal Stress and Strain of Concrete on Cross-Section at Mid-Span}

Figures 19 and 20 show the distributions of the longitudinal strain and the longitudinal stress of concrete on the cross-section at mid-span respectively $\left(D_{\mathrm{s}}=400 \mathrm{~mm}, t_{\mathrm{s}}=9.31 \mathrm{~mm}\right.$, $L_{0}=4000 \mathrm{~mm}, f_{\mathrm{y}}=345 \mathrm{MPa}, f_{\mathrm{cu}}=60 \mathrm{MPa}, \xi_{\mathrm{cf}}=0.115, \eta=0.13, E_{\mathrm{s}}=206 \mathrm{GPa}, v_{\mathrm{s}}=0.3$, $E_{\mathrm{c}}=4700 \sqrt{f_{\mathrm{c}}{ }^{\prime}} \mathrm{MPa}$, (where $f_{\mathrm{c}}{ }^{\prime}$ is strength of the cylinder concrete specimens, and $f_{\mathrm{c}}{ }^{\prime} \approx 0.8 f_{\mathrm{cu}}$ ), Poisson's ratio of the concrete $\left(v_{\mathrm{c}}\right)$ was 0.2$)$. 

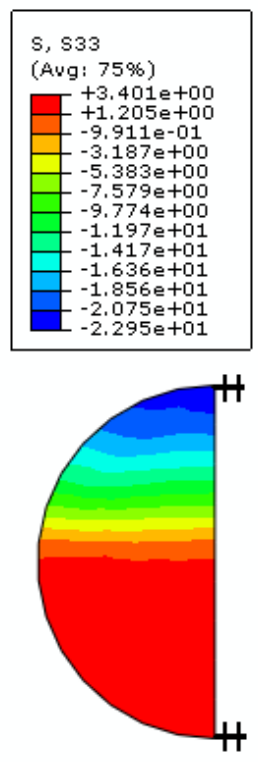

(a) Point 1
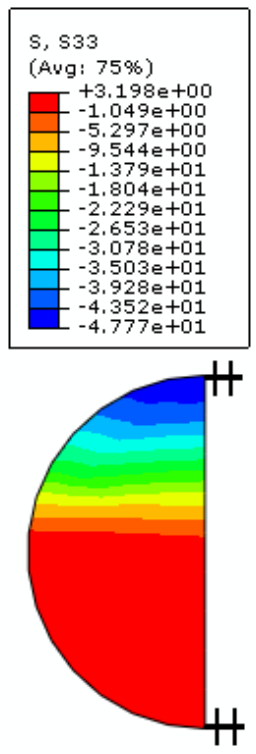

(b) Point 2
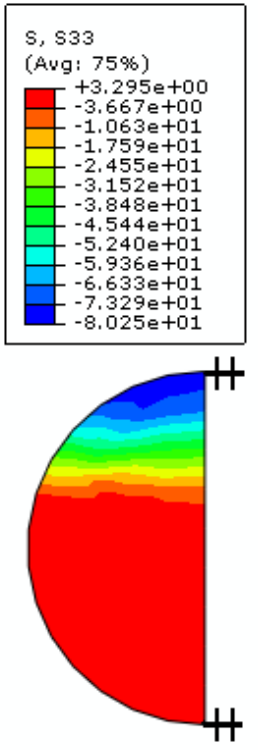

(c) Point 3

Figure 19. Longitudinal Stress Distribution of Concrete on Cross-Section at Mid-span
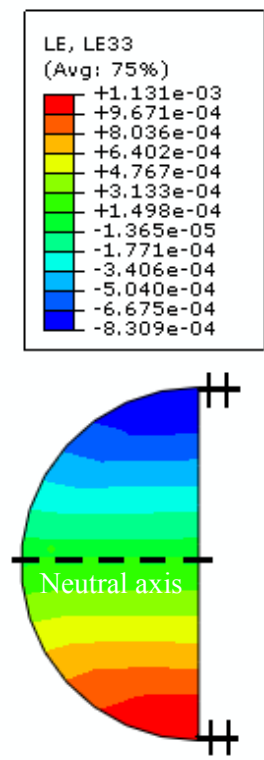

(a) Point 1
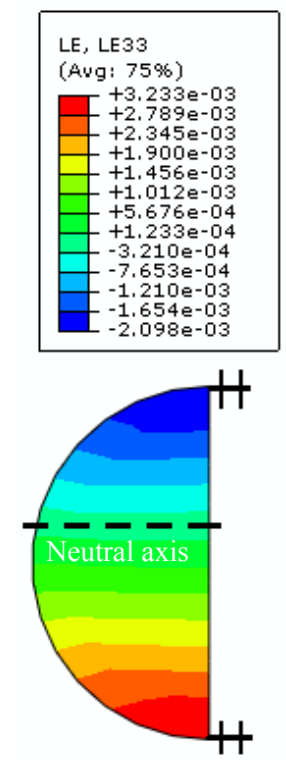

(b) Point 2
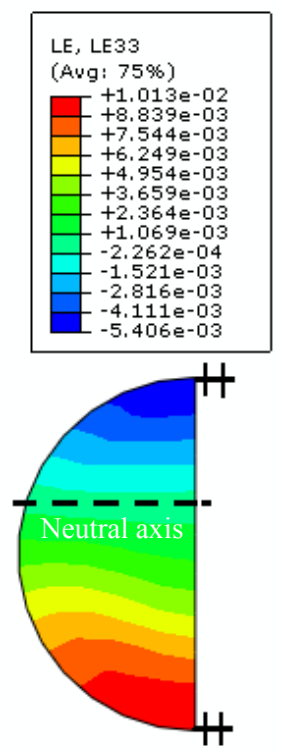

(c) Point 3

Figure 20. Longitudinal Strain Distribution of Concrete on Cross-Section at Mid-Span

It is found that the neutral axis moves toward the compressive region gradually with the increase of the curvature at the mid-span, and this is in accordance with experimental results as shown in Figure 13. In elastic stage (before point 1), the neutral axis is very close to the centroid of the cross-section, and the steel tube and CFRP are both in elastic stage and the maximum longitudinal stress of the compressive concrete is less than $f_{\mathrm{c}}{ }^{\prime}$. In the elasto-plastic stage (between point 1 and point 2), plastic region forms. In this stage, the longitudinal CFRP is not fractured, and it can still restrict the deformation of the flexural member. At point 2, strain of the longitudinal CFRP reaches 
about 1000qe and the longitudinal CFRP begins to fracture. The maximum longitudinal stress of the concrete in the compressive region is close to $f_{\mathrm{c}}{ }^{\prime}$. In the stage between point 2 and point 3 , the longitudinal stress of the steel tube increases continuously with the development of the deflection. The area of the tensile concrete region increases. At point 3, the maximum longitudinal stress of the compressive concrete exceeds $f_{\mathrm{c}}{ }^{\prime}$.

The longitudinal stress distribution of the concrete in axial direction is shown in Figure 21. The longitudinal stress in pure-bending segment of the member distributes uniformly in axial direction. The maximum longitudinal stress is located at the extreme fiber of the specimen.

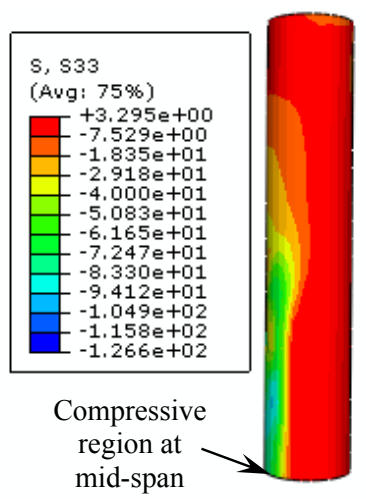

(a) Point 1

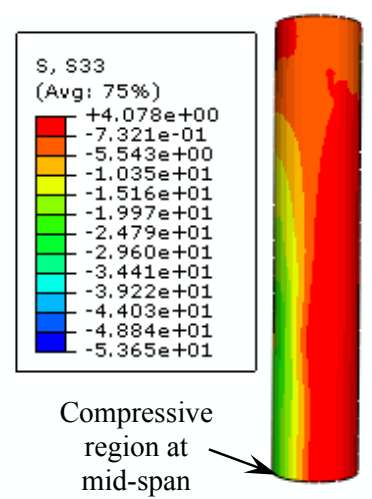

(b) Point 2

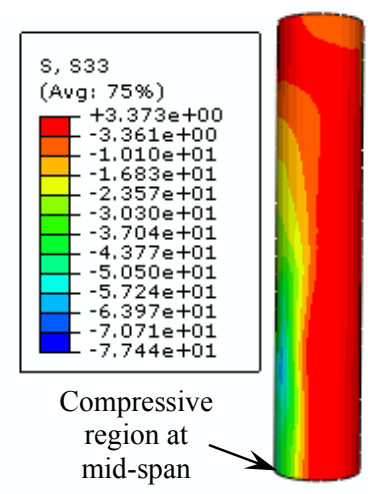

(c) Point 3

Figure 21. Distribution of Longitudinal Stress of Concrete along Axial Direction

\subsection{Influence of $\eta$}

Figure 22 shows the influence of $\eta$ on the position of the neutral axis on the cross-section at mid-span during elasto-plastic stage $\left(D_{\mathrm{s}}=160 \mathrm{~mm}, t_{\mathrm{s}}=4.5 \mathrm{~mm}, f_{\mathrm{y}}=345 \mathrm{MPa}, f_{\mathrm{cu}}=60 \mathrm{MPa}\right.$, $L_{0}=1400 \mathrm{~mm}, \quad \xi_{\mathrm{cf}}=0.1, \quad \eta=0-0.4, \quad E_{\mathrm{s}}=206 \mathrm{GPa}, \quad v_{\mathrm{s}}=0.3, \quad E_{\mathrm{c}}=4700 \sqrt{f_{\mathrm{c}}{ }^{\prime}} \mathrm{MPa}, \quad$ and $\left.v_{\mathrm{c}}=0.2\right)$. The neutral axis has a little offset toward the tensile region of the concrete.

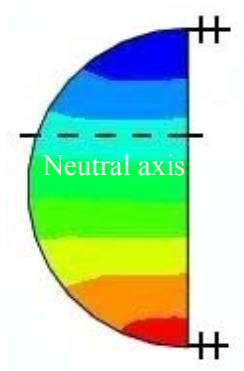

(a) $\eta=0$

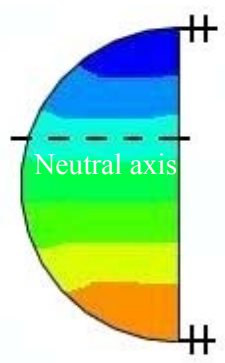

(b) $\eta=0.14$

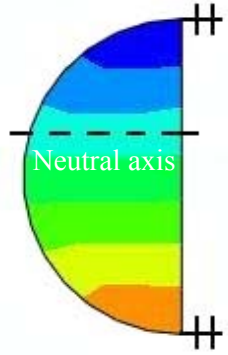

(c) $\eta=0.27$

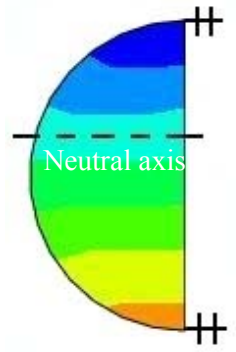

(d) $\eta=0.4$

Figure 22. Influence of $\eta$ on Position of Neutral Axis

Figure 23 shows the effect of $\eta$ on the longitudinal stress distribution on the cross-section at mid-span. It is clear that the longitudinal compressive stress of the concrete increases a little as $\eta$ increases. 


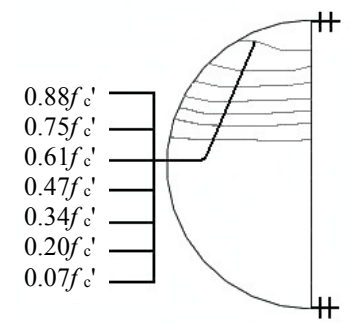

(a) $\eta=0$

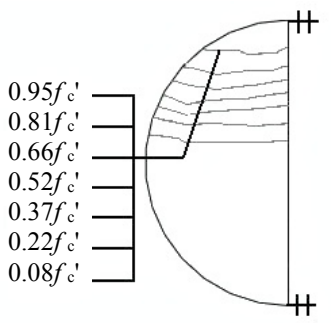

(b) $\eta=0.14$

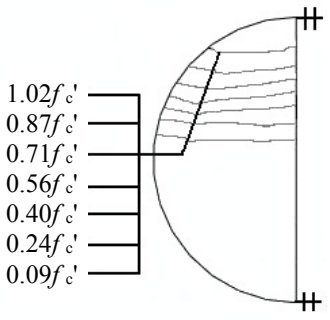

(c) $\eta=0.27$

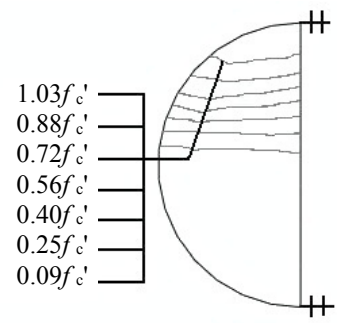

(d) $\eta=0.4$

Figure 23. Influence of $\eta$ on Distribution of Longitudinal Stress of Concrete

\subsection{Interaction Force between Concrete and Steel Tube}

Figure 24 shows the interaction forces $(p)$ between the concrete and the outer tube on the cross-section at mid-span $\left(D_{\mathrm{s}}=160 \mathrm{~mm}, t_{\mathrm{s}}=4.5 \mathrm{~mm}, f_{\mathrm{y}}=345 \mathrm{MPa}, f_{\text {cu }}=60 \mathrm{MPa}\right.$, $L_{0}=1400 \mathrm{~mm}, \quad \xi_{\mathrm{cf}}=0.0976, \eta=0.169, \quad E_{\mathrm{s}}=206 \mathrm{GPa}, \quad v_{\mathrm{s}}=0.3, \quad E_{\mathrm{c}}=4700 \sqrt{f_{\mathrm{c}}} \mathrm{MPa}$, and $\left.v_{\mathrm{c}}=0.2\right)$. Interaction force with a large magnitude also exists between the tensile steel tube and the concrete. However, it is different in essence for the interaction forces in the compressive region and in the tensile region of the concrete. In the compressive region, steel tube restricts the expansion of concrete, which produces confinement force. While in the tensile region, the steel tube is under tension in longitudinal direction but under contraction in transverse direction. Concrete also contracts in transverse direction. However, the transverse deformation of the concrete is much smaller than that of the steel tube (especially after the cracking of the concrete). Thus, the transverse deformation of the steel tube is restrained by the concrete, and the reaction force between steel tube and concrete then initiates. However, this interaction force is not the confinement force.

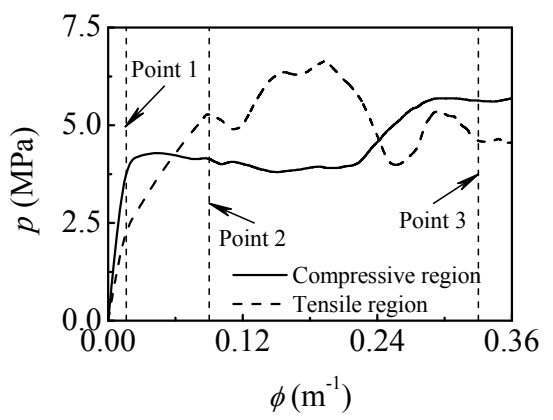

Figure 24. Interaction Force between Outer Tube and Concrete on Cross-Section at Mid-Span

\section{FLEXURAL LOAD CARRYING CAPACITY}

\subsection{Definition of Flexural Load Carrying Capacity}

The calculated results of the FE models $\left(f_{\mathrm{y}}=235-390 \mathrm{MPa}, f_{\mathrm{cu}}=30-120 \mathrm{MPa}, \xi_{\mathrm{s}}=0.2-4\right.$, $\xi_{\mathrm{cf}}=0-0.6, \eta=0-0.9, E_{\mathrm{s}}=206 \mathrm{GPa}, v_{\mathrm{s}}=0.3, E_{\mathrm{c}}=4700 \sqrt{f_{\mathrm{c}}{ }^{\prime}} \mathrm{MPa}$, and $\left.v_{\mathrm{c}}=0.2\right)$ show that the bending moment corresponding to the tensile strains at the extreme fiber reaching $\varepsilon_{\max }$ is the flexural load carrying capacity $\left(M_{\mathrm{u}}\right)$, and $\varepsilon_{\max }$ is defined in this study as follow: 
$\varepsilon_{\max }=2837+166800 / D_{\mathrm{s}}$

where $D_{\mathrm{s}}$ is in $\mathrm{mm}$.

Eq. (10) is obtained using regression analysis based on a parametric study on the calculated FE models. In Eq. (10), the bending moment at this time $\left(\varepsilon_{\max }\right)$ is larger than the elastic limit value but less than the plastic ultimate moment. Partial section of the steel tube is already in yielding state, and the deflection at this time is about $L_{0} / 100$.

It is clarified here that $M_{\mathrm{u}}{ }^{\mathrm{t}}$ shown in Figure 10 is actually determined by $\varepsilon_{\max }$. In Eq. (10), $\varepsilon_{\max }$ of each specimen can be firstly calculated. The bending moment corresponding to $\varepsilon_{\max }$ is then defined as $M_{\mathrm{u}}{ }^{\mathrm{t}}$.

\subsection{Parametric Equation of Load Carrying Capacity}

The flexural load carrying capacity of the member with only transverse CFRP $\left(M_{0}\right)$ is determined firstly. $M_{0}$ is mainly related to the flexural modulus $\left(W_{\mathrm{cfscm}},=\pi D_{\mathrm{s}}^{3} / 32\right)$, the total confinement coefficient $(\xi)$ (Che, Wang and Shao [15]) and the index of axial compressive load carrying capacity $\left(f_{\text {cfscy }}\right)$ (Che, Wang and Shao [15]) of C-CF-CFRP-ST stub columns. Based on a parametric study on amount of FE models, the relationship between $\gamma=M_{0} /\left(W_{\text {cfscm }} f_{\text {cfscy }}\right)$ and $\xi$ is obtained, and it is shown in Figure 25 (a).

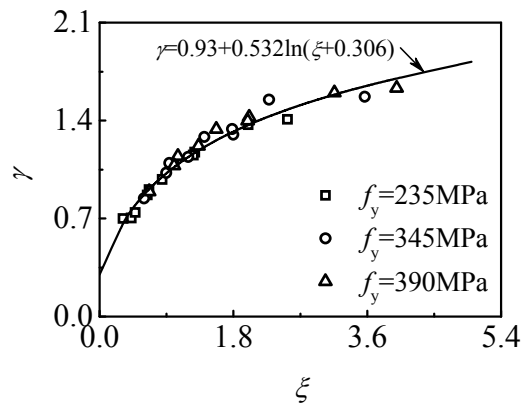

(a) $\gamma-\xi$ Relationship

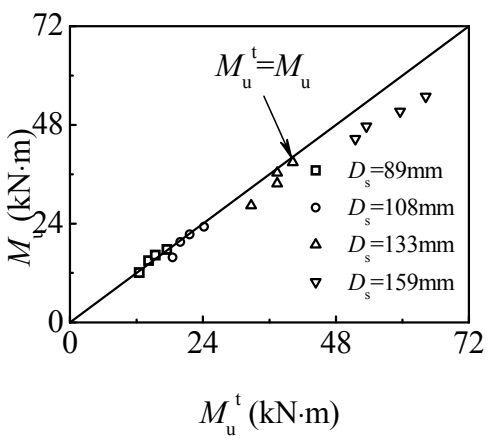

(b) Comparison between $M_{\mathrm{u}}$ and $M_{\mathrm{u}}{ }^{\mathrm{t}}$

Figure 25. Flexural Load Carrying Capacity

The relationship between $\gamma$ and $\xi$ can also be presented as well and it is listed as follow:

$$
\begin{aligned}
& \gamma=0.93+0.532 \ln (\xi+0.306) \\
& \xi=\xi_{\mathrm{s}}+\xi_{\mathrm{cf}}
\end{aligned}
$$

Hence

$$
M_{0}=\gamma W_{\text {cfscm }} f_{\text {cfscy }}
$$


where

$f_{\text {cfscy }}=\left[1.14+1.02\left(\xi_{\mathrm{s}}+3 \xi_{\mathrm{cf}}\right)\right] f_{\mathrm{ck}}$

When the member has both transverse and longitudinal CFRPs, the relationship between $\gamma_{\mathrm{m}}=M_{\mathrm{u}} /\left(W_{\text {cfscm }} f_{\text {cfscy }}\right)$ and $\eta$ can be obtained as follow

$\gamma_{\mathrm{m}}=\gamma+(0.3+0.2 \xi) \eta$

Thus, the flexural load carrying capacity of the C-CF-CFRP-ST members $\left(M_{\mathrm{u}}\right)$ is given as follow:

$M_{\mathrm{u}}=\gamma_{\mathrm{m}} W_{\text {cfscm }} f_{\text {cfscy }}$

\subsection{Validation of Equation}

Figure 25 (b) displays comparison between the calculated flexural load carrying capacity $M_{\mathrm{u}}$ and the tested value $M_{\mathrm{u}}{ }^{\mathrm{t}}$. The average value of $M_{\mathrm{u}} / M_{\mathrm{u}}{ }^{\mathrm{t}}$ is 0.96 , and the mean square error is 0.07 . That means the two results agree well.

\section{CONCLUSIONS}

Based on the experimental study, the finite element simulation, and the theoretical analysis, the following conclusions can be drawn: (1) The $M-\phi$ curves at mid-span of circular concrete filled CFRP-steel tubular flexural specimens without longitudinal CFRP reinforcement are similar to those of the corresponding circular concrete filled steel tubular flexural members, while $M-\phi$ curves at mid-span of C-CF-CFRP-ST flexural specimens with longitudinal CFRP reinforcement can be defined as elastic stage, elasto-plastic stage and softening stage. Thereafter, the rest of the curves are similar to those of the corresponding C-CFST flexural members. The stiffness of the specimen can be enhanced by the longitudinal CFRP. (2) The steel tube and the CFRP tube can cooperate well both in transverse and in longitudinal directions. The distribution of the longitudinal strain of the specimens over the depth of the cross-section meets the plane section assumption approximately. The shape of the deflection-curve is basically similar to half sinusoidal curves. (3) The finite element simulation results of the deformation and $M-\phi$ curves of C-CF-CFRP-ST flexural members agree well with experimental results. (4) Interaction forces between the outer tube and the core concrete exist not only in the compressive region but also in the tensile region. However, the mechanisms of the interaction forces in the two regions are essentially different. (5) The flexural load carrying capacity of C-CF-CFRP-ST is defined, and the calculating equation of the flexural load carrying capacity is given.

\section{ACKNOWLEDGEMENTS}

The research reported in the paper is part of the Project 51378320 supported by Natural Science Foundation of China (NSFC) and the Project 2013003004 supported by Public Welfare Foundation of Liaoning Province, P R China. Their financial supports are highly appreciated. 


\section{NOMENCLATURE}

\begin{tabular}{|c|c|}
\hline$A_{\mathrm{c}}$ & : Cross-sectional area of concrete \\
\hline$A_{\mathrm{cfl}}$ & : Cross-sectional area of longitudinal CFRP \\
\hline$A_{\mathrm{cft}}$ & : Cross-sectional area of transverse CFRP \\
\hline$A_{\mathrm{s}}$ & : Cross-sectional area of steel tube \\
\hline C-CF-CFRP-ST & : Circular concrete filled CFRP-steel tubes \\
\hline C-CFST & : Circular concrete filled steel tubes \\
\hline CF-CFRP-ST & : Concrete filled CFRP steel tubes \\
\hline CF-CFRP-T & : Concrete filled CFRP tubes \\
\hline CFRP & : Carbon fiber reinforced polymer \\
\hline CFST & : Concrete-filled steel tubes \\
\hline CFT & : Concrete-filled tubes \\
\hline$D_{\mathrm{s}}$ & : Outer diameter of steel tube \\
\hline$E_{\mathrm{c}}$ & : Elastic modulus of concrete \\
\hline$E_{\mathrm{cf}}$ & : Elastic modulus of carbon fiber sheets \\
\hline$E_{\mathrm{s}}$ & : Elastic modulus of steel tube \\
\hline$f_{\text {cfscy }}$ & $\begin{array}{l}\text { : Load carrying capacity index of axial compressive strength of circular concrete } \\
\text { filled CFRP-steel tubular (C-CF-CFRP-ST) stub columns }\end{array}$ \\
\hline$f_{\mathrm{cfl}}$ & : Ultimate tensile strength of longitudinal CFRP \\
\hline$f_{\mathrm{cft}}$ & : Ultimate tensile strength of transverse CFRP \\
\hline$f_{\mathrm{ck}}$ & : Characteristic axial compressive strength of concrete \\
\hline$f_{\mathrm{cu}}$ & : Cubic strength of concrete \\
\hline$f_{\mathrm{u}}$ & : Ultimate strength of steel tube \\
\hline$f_{\mathrm{y}}$ & : Yield strength of steel tube \\
\hline$f_{\mathrm{c}}^{\prime}$ & : Compressive strength of cylinder concrete specimens \\
\hline$f_{\mathrm{cf}}^{\prime}$ & : Tension strength of carbon fiber sheet \\
\hline$K_{\text {ie }}$ & : Initial flexural stiffness \\
\hline$K_{\mathrm{se}}$ & : Service flexural stiffness \\
\hline$L$ & : Length of specimens \\
\hline$L_{0}$ & : Net span of specimens \\
\hline$M$ & : Moment at mid-span \\
\hline$M_{0}$ & $\begin{array}{l}\text { : Flexural load carrying capacity of circular concrete filled CFRP-steel tubular } \\
\text { (C-CF-CFRP-ST) member with only transverse CFRP }\end{array}$ \\
\hline$M_{\mathrm{u}}$ & $\begin{array}{l}\text { : Flexural load carrying capacity of circular concrete filled CFRP-steel tubular } \\
\text { (C-CF-CFRP-ST) member with both transverse CFRP and longitudinal CFRP }\end{array}$ \\
\hline$M_{\mathrm{u}}^{\mathrm{t}}$ & : Tested value of $M_{\mathrm{u}}$ \\
\hline$m$ & : Number of transverse CFRP layer \\
\hline$m^{\prime}$ & : Number of longitudinal CFRP layer(s) \\
\hline$P$ & : Lateral load \\
\hline$p$ & : Interaction force between concrete and outer tube \\
\hline$t_{\mathrm{cf}}$ & : Thickness of one layer carbon fiber sheet \\
\hline$t_{\mathrm{s}}$ & : Wall thickness of steel tube \\
\hline
\end{tabular}




$\begin{array}{ll}u & : \text { Deflection } \\ u_{\mathrm{m}} & : \text { Deflection at mid-span } \\ v_{\mathrm{c}} & : \text { Poisson's ratio of concrete } \\ v_{\mathrm{s}} & : \text { Poisson's ratio of steel tube } \\ W_{\mathrm{cfscm}} & : \text { Flexural modulus } \\ w_{\mathrm{cf}} & : \text { Density of carbon fiber sheet } \\ \delta_{\mathrm{cf}} & : \text { Elongation percentage of carbon fiber sheet } \\ \Delta_{\mathrm{cn}} & : \text { Distance measured from neutral axis to centroid axis } \\ \varepsilon_{\mathrm{cf}} & : \text { Strain of CFRP } \\ \varepsilon_{\mathrm{cfl}} & : \text { Strain of longitudinal CFRP } \\ \varepsilon_{\mathrm{cft}} & : \text { Strain of transverse CFRP } \\ \varepsilon_{\mathrm{cffr}} & : \text { Rupture strain of longitudinal CFRP } \\ \varepsilon_{\mathrm{cffr}}{ }^{\prime} & : \text { Rupture strain of longitudinal CFRP for each specimen measured from test } \\ \varepsilon_{\mathrm{cftr}} & : \text { Rupture strain of transverse CFRP } \\ \varepsilon_{1} & : \text { Longitudinal strain } \\ \varepsilon_{\mathrm{max}} & : \text { Tensile strain at extreme fiber of specimens corresponding to } M_{\mathrm{u}} \\ \varepsilon_{\mathrm{sl}} & : \text { Longitudinal strain of steel tube } \\ \varepsilon_{\mathrm{st}} & : \text { Transverse strain of steel tube } \\ \varepsilon_{\mathrm{t}} & : \text { Transverse strain } \\ \phi & : \text { Curvature at mid-span } \\ \gamma & : \text { Coefficient, }=M_{\mathrm{o}} /\left(W_{\mathrm{cfscm}} f_{\mathrm{cfscy}}\right) \\ \gamma_{\mathrm{m}} & : \text { Coefficient, }=M_{\mathrm{u}} /\left(W_{\mathrm{cfscm}} f_{\mathrm{cfscy}}\right) \\ \eta & : \text { Strengthening factor of longitudinal CFRP } \\ \sigma_{\mathrm{cf}} & : \text { Stress of CFRP } \\ \xi & : \text { Total confinement factor } \\ \xi_{\mathrm{cf}} & : \text { Confinement factor of CFRP } \\ \xi_{\mathrm{s}} & : \text { Confinement factor of steel tube } \\ & \end{array}$

\section{REFERENCES}

[1] Han, L. H., "Tests on Concrete Filled Steel Tubular Columns with High Slenderness Ratio", Advances in Structural Engineering, 2000, Vol. 3, No. 4, pp. 337-344.

[2] Tao, Z., Uy, B., Han, L. H. and Wang, Z. B., "Analysis and Design of Concrete-filled Stiffened Thin-walled Steel Tubular Columns under Axial Compression", Thin-Walled Structures, 2009, Vol. 47, No. 12, pp. 1544-1556.

[3] Georgios, G. and Lam, D., "Axial Capacity of Circular Concrete-filled Tube Columns", Journal of Constructional Steel Research, 2004, Vol. 60, No. 7, pp. 1049-1068.

[4] Uy, B., "Strength of Short Concrete Filled High Strength Steel Box Columns", Journal of Constructional Steel Research, 2001, Vol. 57, No. 2, pp. 113-134.

[5] Han, L. H. and Yang, Y. F., "Cyclic Performance of Concrete-filled Steel CHS Columns under Flexural Loading”, Journal of Constructional Steel Research, 2005, Vol. 61, No. 4, pp. 423-452. 
[6] Han, L. H. and Li, W., "Seismic Performance of CFST Column to Steel Beam Joint with RC Slab: Experiments", Journal of Constructional Steel Research, 2010, Vol. 66, No. 11, PP. 1374-1386.

[7] Han, L. H., Wang, W. H. and Yu, H. X., "Experimental Behaviour of Reinforced Concrete (RC) Beam to Concrete-filled Steel Tubular (CFST) Column Frames Subjected to ISO-834 Standard Fire", Engineering Structures, 2010, Vol. 32, No. 10, pp. 3130-3144.

[8] Han, L. H., Hou, C. and Wang, Q. L., "Square Concrete Filled Steel Tubular (CFST) Members under Loading and Chloride Corrosion: Experiments", Journal of Constructional Steel Research, 2012, Vol. 71, No. 1, pp. 11-25.

[9] Wang, Y. C. and Restrepo, J. I., "Investigation of Concentrically Loaded Reinforced Columns Confined with Glass Fiber-reinforced Polymer Jackets", Structure Journal, 2001, Vol. 98, No. 3, pp. 377-385.

[10] Teng, J. G., Chen, J. F., Smith, S. T. and Lam, L., "FRP Strengthened RC Structures", John Wiley \& Sons Ltd., 2002.

[11] Han, L. H., Tao, Z. and Wang, W. D., "Advanced Composite and Mixed Structures-Testing, Theory and Design Approach", China Science Press, 2009. (in Chinese)

[12] Tao, Z., Han, L. H. and Wang, L. L., "Compressive and Flexural Behaviour of CFRP Repaired Concrete-filled Steel Tubes after Exposure to Fire", Journal of Constructional Steel Research, 2007, Vol. 63, No. 8, pp. 1116-1126.

[13] Xiao, Y., He, W. H. and Choi, K. K., "Confined Concrete-filled Tubular Columns.” Journal of Structural Engineering, 2005, Vol. 131, No. 3, pp. 488-497.

[14] Choi, K. K. and Xiao, Y., "Analytical Model of Circular CFRP Confined Concrete-Filled Steel Tubular Columns under Axial Compression", Journal of Composites for Construction, 2010, Vol. 14, No. 1, pp. 125-133.

[15] Che, Y., Wang, Q. L. and Shao, Y. B., "Compressive Performances of the Concrete Filled Circular CFRP-steel Tube (C-CFRP-CFST)", International Journal of Advanced Steel Construction, 2012, Vol. 8, No. 4, pp. 311-338.

[16] Han, L. H., "Flexural Behaviour of Concrete Filled Steel Tubes", Journal of Constructional Steel Research, 2004, Vol. 60, No. 2, pp. 313-337.

[17] Han, L. H., "Fire Resistance of Concrete Filled Steel Tubular Columns", Advances in Structural Engineering, 1998, Vol. 2, No. 1, pp. 35-39.

[18] Han, L. H., Yao, G. H. and Zhao, X. L., "Behavior and Calculation on Concrete-filled Steel CHS (Circular Hollow Section) Beam-columns", Steel and Composite Structures, 2004, Vol. 4, No. 3, pp. 169-188.

[19] Verma, A. H., Ricles, J. M., Sause, R. and Lu, L. W., "Seismic Behaviour and Modeling of High-strength Composite Concrete-filled Steel Tube (CFT) Beam-columns", Journal of Constructional Steel Research, 2002, Vol. 58, No. 5-8, pp. 725-758.

[20] Han, L. H., Zhao, X. L. and Tao, Z., "Tests and Mechanics Model of Concrete-filled SHS Stub Columns, Columns and Beam-columns", Steel and Composite Structures, 2001, Vol. 1, No. 1, pp. 51-74.

[21] Yu, T., Wong, Y. L., Teng, J. G., Dong, S. L. and Lam, E.S.S., "Flexural Behavior of Hybrid FRP-concrete-steel Double-skin Tubular Members", Journal of Composites for Construction, 2006, Vol. 10, No. 5, pp. 443-452.

[22] Han, L. H., Liu, W. and Yang, Y. F., "Behaviour of Concrete-filled Steel Tubular Stub Columns Subjected to Axially Local Compression", Journal of Constructional Steel Research, 2008, Vol. 64, No. 4, pp. 377-387. 